\title{
The effect of pyridoxin deficiency on certain organs of the rat
}

\author{
By CYNTHIA D. COMBRIDGE \\ Department of Physiology, Queen Elizabeth College \\ (University of London), Campden Hill Road, London, W. 8
}

(Received 6 June 1956)

\begin{abstract}
Some preliminary studies on the histological appearance of certain organs of the pyridoxin-deficient rat have been made. During an attempt to interpret the results of these studies, it was found that conflicting accounts of adrenal changes in pyridoxin deficiency occurred in the literature. Further experiments were undertaken in an attempt to clear up this point and to discover the relative rates at which changes took place in the organs studied.
\end{abstract}

\section{EXPERIMENTAL}

Diets. The three diets employed were all fed $a d$ lib. and were as follows: A, basal purified diet with all vitamin supplements except pyridoxin; $\mathrm{B}$, basal purified diet with all vitamin supplements; $C$, normal stock diet of mixed grains, meat, fish, bread and milk.

The basal diet and vitamins $\mathrm{A}, \mathrm{D}$ and $\mathrm{E}$ and certain of the B-vitamins (excepting pyridoxin) were given exactly as described by Batchen, Cheesman, Copping \& Trusler (1955). No vitamin $B_{12}$ was given, as it appears to be unnecessary for the growth of pyridoxin-deficient rats (Copping, 1956). A solution of pyridoxin hydrochloride was administered separately at a level of $\mathrm{r} o \mu \mathrm{g}$ daily. Of the female rats, two that had been on the pyridoxin-deficient diet for 8 weeks were accidentally given a single dose of $10 \mu \mathrm{g}$ of vitamin $\mathrm{B}_{6}$ a fortnight before they were killed. The results for these rats differed from those for others of the same group, and special reference will be made to them later.

Animals and their treatment. The seventy-two animals used in this experiment were black-and-white hooded rats of the Lister strain from the stock maintained at Queen Elizabeth College. Weanling rats weighing $3^{6-58} \mathrm{~g}$, but of fairly constant weight within the litter, were used. They were put into separate cages when 3 weeks old and fed on one of the two purified diets used. Litter-mates were fed on the laboratory stock diet as controls. Litters of from six to nine animals were used, excepting one litter of three males (which was used to complete the numbers of rats). Litter-mates and sexes were evenly distributed between the groups. Animals were maintained on one of the three diets for periods of 3,6 or 8 weeks after weaning. Four male and four female rats on each of the three diets were killed after each of these periods. Originally it had been planned that the last twenty-four rats should be killed 9 weeks after weaning, but the rats on the pyridoxin-deficient diet were in such poor condition after 8 weeks' deprivation that their survival for another week was doubtful. 
The method of killing was to inject intraperitoneally (according to the size of the rat) $0 \cdot 25^{-1} \cdot 0 \mathrm{ml}$. of a $33 \%$ dilution of Nembutal (Abbot Laboratories Ltd, London). The organs were removed while the animal was under deep anaesthesia. The animals were not frightened by this technique, as they often are when coal-gas poisoning is used.

Weighing. The organs were removed in the following order: first, part of the left lobe of the liver, then both adrenals, then the spleen and the thymus. The liver was placed directly into fixative, but the other organs were dissected away from surrounding tissue and weighed before fixing. Both adrenals were weighed together. Especial care was taken to ensure that the mediastinal lymph node was removed from the thymus before weighing (Agnew, r948).

Histological technique. In no instance was there a delay of more than $15 \mathrm{~min}$ between the opening of the abdominal cavity and the immersion of all the tissues in fixing fluid. Portions of the left lobe of the liver were placed in Carnoy's fluid, to be stained for glycogen by Best's method and for reticulin by Laidlaw's method. Other portions of liver were placed in a $10 \%(\mathrm{v} / \mathrm{v})$ solution of formaldehyde in $0.9 \%$ saline for the staining of lipids with Sudan III. The adrenals were separated after weighing. The right adrenal of each rat was placed in Susa's fluid for staining with Laidlaw's reticulin stain and with general stains and the left adrenal in $10 \%$ formalin saline for Sudan III staining. After weighing, the spleen and thymus were both fixed in Susa's fluid, to be stained with Laidlaw's reticulin and by general methods.

\section{RESULTS}

General appearance and growth. Weight changes may be seen in Fig. I. Rats on diets $\mathrm{B}$ and $\mathrm{C}$ grew steadily. Those on the purified diet B grew more slowly than those on the stock diet $\mathrm{C}$. Rats on the pyridoxin-deficient diet A grew much more slowly

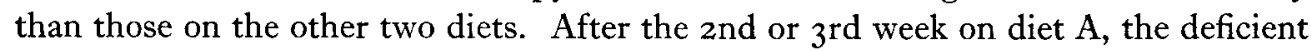
rats were noticeably less lively than those on diets $B$ and $C$. Their coats became rather greasy in appearance, but not harsh to the touch. Rats on the pyridoxin-deficient diet both ate and drank less than the controls with the pyridoxin supplement. Dermatitis began to appear on the paws of the deficient rats after about 6 weeks on the diet. At 8 weeks all deficient rats showed dermatitis and acrodynia of all four paws, with the exception of one of the rats that had been given by mistake a single $10 \mu \mathrm{g}$ dose of pyridoxin 6 weeks after weaning. At autopsy the pyridoxin-deficient rats were found to be markedly depleted of body fat. Even the pads of fat around the kidneys were absent in the 8-week deficient group. Development of the gonads was noticeably retarded in the rats fed on $\operatorname{diet} A$, and it was somewhat slower in rats on diet $B$ than in those on the stock diet C. Presumably the degree of development of the gonads went approximately parallel with the changes in body-weight.

Liver. The organ was not weighed. Sections stained with Scott's haematoxylin and dilute Biebrich Scarlet showed vacuolation of the cells in the centrilobular areas of livers from pyridoxin-deficient rats. The Sudan III stain showed the presence of lipid in areas of the lobules corresponding to those showing vacuolation with the general 
stain. Of the livers from control rats a few also contained some lipid, but it was generally in the portal and not the centrilobular region of the lobule.

Of the eight rats deprived of pyridoxin for 3 weeks, four showed some lipid droplets in the cells of the centrilobular area, although two showed fat around the portal region. After 6 weeks on the vitamin $B_{6}$-deficient diet, six out of eight rats had lipid droplets in the cells of the centrilobular area, one to a very marked degree. Only two of the sixteen control rats of the same age had comparatively small amounts of lipoidal material in the cells of the centrilobular area, although six showed some lipid in the portal regions of the liver lobules.

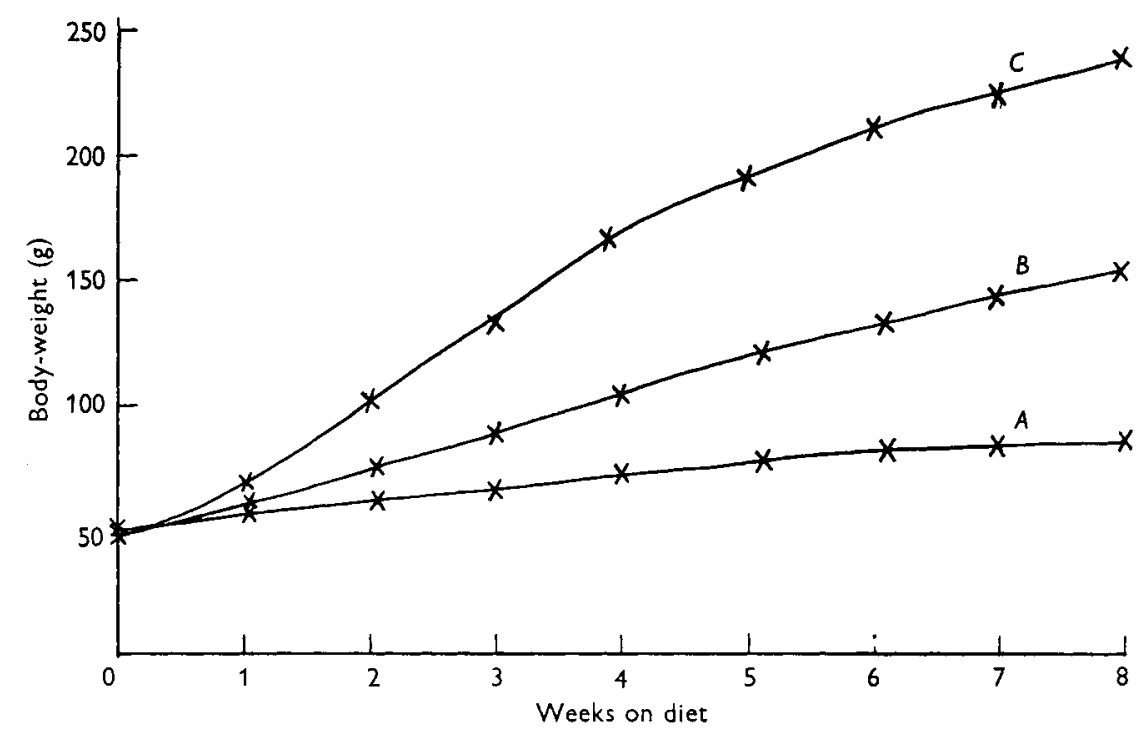

Fig. I. Growth curves of groups of, initially, twenty-four rats maintained from weaning for from o to 8 weeks on (A) a purified diet with all vitamin supplements except pyridoxin, (B) a purified diet with all vitamin supplements, and (C) the ordinary stock diet (see also p. 347.)

The livers of the six animals completely deprived of dietary pyridoxin for 8 weeks all showed heavy lipid infiltration. At autopsy, the liver appeared yellow. The lipid was found in the centrilobular area, and extended to the portal area of the lobule in four rats (see Pl. I). The livers of the two animals given in error a single dose of ro $\mu \mathrm{g}$ pyridoxin after 6 weeks' deprivation, and killed after 2 weeks' further deprivation did not show any lipid. Of the sixteen control rats of the same age only one showed small amounts of centrilobular lipid, and three showed small amounts of lipid in the portal area of the liver lobules. These results are summarized in Table I.

It may be concluded that lipid tends to accumulate in the cells of the central area of the liver lobule during pyridoxin deficiency. The size and number of the lipid droplets increased with the duration of the deficiency. A single dose of pyridoxin given at a time when the lipid deposition was beginning was sufficient to prevent that deposition for at least the next 2 weeks.

On examining the liver histologically, small aggregations of cells resembling lymphoid tissue were found near the portal canals in some sections. These aggregations were 
similar in appearance to the 'portal inflammatory reaction' described by Himsworth (1950) as occurring in livers of rats with lipid in the cells of the centrilobular region as a result of injecting chloroform or carbon tetrachloride. There was a greater incidence of this portal inflammatory reaction in the pyridoxin-deficient group of rats than in either of the control groups. It was present in twelve out of fourteen deficient rats after 6-8 weeks on the deficient diet and in only nine out of thirty-two controls.

Table. I. Distribution of fat in the livers of rats fed on diet $A$ (purified, with all vitamin supplements except pyridoxin), diet $B$ (purified, with all vitamin supplements), or diet $C$ (stock)

$\begin{array}{cccc}\text { Diet } & \begin{array}{c}\text { After 3 weeks' } \\ \text { deficiency } \\ \text { Centrilobular }\end{array} & \begin{array}{c}\text { After 6 weeks' } \\ \text { deficiency } \\ \text { Centrilobular } \\ (++)\end{array} & \begin{array}{c}\text { After 8 weeks' } \\ \text { deficiency } \\ \text { Centrilobular } \\ (+++)\end{array} \\ \text { B } & \text { None } & \begin{array}{c}\text { Portal } \\ (+)\end{array} & \text { None } \\ \text { C } & \text { None } & \text { Portal mainly } & \text { Portal } \\ & & (+) & + \\ & & & \end{array}$

The Laidlaw's reticulin stain revealed no significant changes in the amount of reticular tissue in the liver, either between groups of rats on different diets or between rats of different ages.

The extent and distribution of glycogen, as shown by Best's carmine stain, was not correlated with the nutritional state of the animal. However, estimations of the glycogen contents of the whole livers would have to be made before it could be said with any certainty that they were unaltered during pyridoxin deficiency.

Adrenals. The adrenals of the female rats of all ages and groups, excepting those on $\operatorname{diet} \mathrm{A}$ for 3 weeks, were found significantly heavier than those of the males, as may be seen from Table 2. This finding is well known and is doubtless associated with the development of the female gonads.

Table 2. Mean body-weight and weights of both adrenals, spleen and thymus of groups of eight rats after different periods on diet $A$ (purified with all vitamin supplements except pyridoxin), diet $B$ (purified with all vitamin supplements) or diet $C$ (stock)

\begin{tabular}{|c|c|c|c|c|c|c|c|c|c|c|c|c|c|c|c|c|c|c|}
\hline \multirow{3}{*}{$\begin{array}{l}\text { Time } \\
\text { on } \\
\text { diet } \\
\text { (weeks) }\end{array}$} & \multirow{2}{*}{\multicolumn{3}{|c|}{$\begin{array}{l}\text { Body-weight } \\
\text { (g) of rats } \\
\text { on diet: }\end{array}$}} & \multicolumn{9}{|c|}{$\begin{array}{l}\text { Weight of both adrenals (mg/ioo g body- } \\
\text { weight) of rats on diet }\end{array}$} & \multirow{2}{*}{\multicolumn{3}{|c|}{$\begin{array}{c}\text { spleen } \\
\text { (mg/roog } \\
\text { body-weight) } \\
\text { of rats } \\
\text { on diet }\end{array}$}} & \multirow{2}{*}{\multicolumn{3}{|c|}{$\begin{array}{l}\text { thymus } \\
\text { (mg/roo g } \\
\text { bodyeight) } \\
\text { of rats } \\
\text { on diet }\end{array}$}} \\
\hline & & & & & A & & & B & & & $\mathrm{C}$ & & & & & & & \\
\hline & A & B & C & M. & F. & Mean & M. & F. & Mean & M. & F. & Mean & A & B & C & A & B & C \\
\hline 3 & 65 & 88 & I 33 & $35^{\circ} 4$ & $34^{\circ}$ & & 28 & $29 \cdot 2$ & $28 \cdot 7$ & $23 \cdot 6$ & $26 \cdot 8$ & $25 \cdot 2$ & 242 & 287 & 339 & 164 & 231 & 257 \\
\hline 6 & 80 & I 3 I & 210 & $26 \cdot 3$ & $33 \cdot 1$ & & 23. & $28 \cdot 3$ & 25 & 16.7 & & 9 & 202 & 223 & 224 & & 189 & $\begin{array}{l}194 \\
\end{array}$ \\
\hline 8 & 85 & 152 & 239 & $28 \cdot 2$ & 27.9 & $28 \cdot 1$ & I 8.8 & $26 \cdot I$ & $22 \cdot 5$ & I 5.5 & $29 \cdot 2$ & $22 \cdot 4$ & 202 & I 89 & 203 & $36 \cdot 3^{*}$ & I 94 & 148 \\
\hline
\end{tabular}

* This group only includes the six rats totally deprived of pyridoxin for 8 weeks. The two females given $10 \mu \mathrm{g}$ each of pyridoxin after 6 weeks' deficiency and killed at 8 weeks had thymus weights of 90 and I $6 \mathrm{mg} / \mathrm{ro0} \mathrm{g}$. Neither the spleens nor the adrenals of these two rats were significantly different in weight from those of other members of the group. 
The vitamin $\mathrm{B}_{6}$-deficient rats had lower absolute adrenal weights than rats of either of the other groups, but the adrenal weights relative to body-weight, as given in Table 2, were significantly higher in the deficient groups $(P<0 \cdot 01)$. No inanition controls were used in these experiments.

Histological examination of adrenal sections stained with Scott's haematoxylin and dilute Biebrich Scarlet showed vacuolation of the cells of the adrenal cortex in all sections, but it was far more marked in the pyridoxin-deficient rats at every stage. This vacuolation was especially prominent in the zona fasciculata of the deficient rats (see Pl. I). The frozen sections stained with Sudan III showed the vacuoles to be filled with sudanophilic material. All deficient rats showed in the zona fasciculata sudanophilic deposits heavier than those seen in control rats, and these were especially marked in the group totally deprived of pyridoxin for 8 weeks. The lipid droplets in the cells of this group were of small diameter. The cells of the zona fasciculata were, however, larger than those of control rats. The adrenals of the two rats given ro $\mu \mathrm{g}$ of vitamin $B_{6}$ after 6 weeks' deficiency and killed after 8 weeks' showed little more lipid than those of rats deprived of pyridoxin for only 3 weeks.

The reticulin tissue of the zona reticularis also appeared to be increased in the adrenals of deficient rats, especially in those deprived of the vitamin for 6 weeks or longer.

Spleen. There were great variations in the weight of the individual spleens in each group. Table 2 shows only the average weights of spleens from each group of rats. There was no significant difference in the weight of spleen relative to body-weight, either between the groups of rats on different diets $(P>0.2)$ or between males and females of any group. The histological structures of the spleens of the three groups of rats were similar at all ages. There were, therefore, no obvious changes in weight or structure of this organ as a result of pyridoxin deficiency.

Thymus. The weights of the thymus glands of all groups of rats fed on the pyridoxinfree diet were significantly lower than those of either of the control groups $(P<0 \circ 01)$. The only two rats with thymus weights approaching control level, when expressed as mg thymus/100 g body-weight, were those given a single dose of $10 \mu \mathrm{g}$ pyridoxin after 6 weeks' deprivation. The thymus weights of these two rats were several times larger than those of the remainder of the group, and have therefore not been used in calculating the means shown in Table 2 . There were no marked sex differences in thymus weights expressed as $\mathrm{mg} / \mathrm{roo} \mathrm{g}$ body-weight.

The histological picture was similar to that already described in pyridoxin deficiency (Stoerck \& Eisen, 1946) and in choline deficiency (Christensen \& Griffith, 1942). The gland was atrophied and depleted of lymphocytes, especially in the cortex, and there was increased vascularization of the medulla (see Pl. I). The reticulin stain showed an increased amount of reticular tissue in the medulla and a thickening of the reticular tissue between the lobes of the thymus. All changes were more marked after a longer period of pyridoxin deficiency. The thymus glands of the two rats given a single dose of $10 \mu \mathrm{g}$ pyridoxin resembled those of 3 and 6-week deficient rats rather than those of 8 -week deficient rats in the same group. 


\section{DISCUSSION}

No changes were found in the weights or histological structures of the spleens in pyridoxin-deficient rats. This finding agrees with the results of Agnew \& Cook (I949) though they did not state any specific conclusions. Effects upon the weights and histological structures of both the thymus and adrenal glands were noticeable after only 3 weeks of deprivation. In six of the eight rats fed on the vitamin $\mathrm{B}_{6}$-deficient diet for 6 weeks, the histological effects of the deficiency on thymus and adrenal glands were clear, and all the rats totally deprived of pyridoxin for 8 weeks showed marked effects. The histological changes in the liver only appeared after 6 weeks on the pyridoxin-deficient diet. After 8 weeks' total deprivation all the vitamin $\mathrm{B}_{6}$-deficient rats showed deposition of fat in the centrilobular cells of the liver.

It is clear, therefore, that the histological changes in the adrenal and thymus glands preceded those in the liver. This fact is further supported by results from the two rats deprived of pyridoxin for 8 weeks except for a single dose of ro $\mu$ g of pyridoxin 2 weeks before they were killed. These animals had no histologically demonstrable fat in their livers, but the states of their adrenal and thymus glands resembled those of rats deprived of pyridoxin for 3 weeks.

The effect of the avitaminosis upon adrenal weights is of interest. The adrenal weights relative to body-weights of pyridoxin-deficient rats were significantly greater than those of either control group. Agnew \& Cook (1949) stated that the adrenal weights of their pyridoxin-deficient rats were not significantly different from those of their inanition controls. However, since Sayers \& Sayers (1948) maintained that fasting causes enlargement of the adrenal glands, it was not unlikely that the adrenals of both inanition controls and pyridoxin-deficient rats were enlarged.

The increase in size of the cells of the zona fasciculata in the adrenals of pyridoxindeficient rats, together with the many small droplets of sudanophilic substance in these cells, suggest overactivity of this region. The increased weights of the adrenals also suggest overactivity of that organ, perhaps as a result of prolonged stress. Deane \& Greep (I946) suggest that the zona fasciculata is the cortisone-producing region of the adrenal cortex. It is possible, therefore, that the apparent hyperactivity of the zona fasciculata in the present series of experiments is connected with an increased secretion of cortisone, perhaps resulting from an increased secretion of ACTH by the adenohypophysis (Sayers \& Sayers, 1948). Overactivity of the adrenal cortex with oversecretion of cortisone might well be the cause of the thymic atrophy and the increase in reticular tissue of the thymus and also of the later fatty infiltration of the liver seen in pyridoxin-deficient rats. Stoerck (I950) and Mueller, Weir \& Heinle (I95 I) have shown that cortisone injections together with pyridoxin deficiency have greater effects on lymphosarcoma implants and haematological changes than either agent separately. Is it possible that pyridoxin deficiency causes, perhaps through the agency of ACTH, an increased output of cortisone, which may in turn cause at least some of the other effects of pyridoxin deficiency?

The deposition of fat in the liver in pyridoxin deficiency is centrilobular. In this it resembles the hepatic distribution of fat in choline deficiency (Best, Hartroft, Lucas \& 
Ridout, 1955). This accumulation of fat appears indicative of a metabolic breakdown, since the diet does not contain large amounts of fat, or of a deficiency of choline. It is known that fat deposition in the liver due to various causes is reduced or prevented by adrenalectomy (MacKay \& Barnes, 1937a, b). Certain extracts of the anterior pituitary are also known to cause deposition of fat in the liver. It consequently appears that the fat deposition in the liver during pyridoxin deficiency may well be due to oversecretion of ACTH or of cortisone.

Some explanation is needed of the differences between our results and those of other workers. Stebbins (1950) found no sudanophilic lipids in the zona fasciculata of the adrenals of rats fed for 5 weeks on a diet deficient in pyridoxin. Deane \& Shaw (1947) found augmented quantities of sudanophilic lipids in the adrenal cortices of their rats after 3 weeks' deficiency, but adrenals from rats deprived of pyridoxin for longer periods showed no difference from those of control rats. Nor did these workers find any increased amounts of fat in the livers of their deficient rats. Antopol \& Unna (1942) found less fat in the livers of their pyridoxin-deficient rats than in those of the controls, but also noted enlargement of the zona fasciculata of the adrenals, which contained large vacuolated cells.

Many of the differences between the results of our experiments and those of others may be attributed to differences in the diets used, which could lead to differences in the severity of the signs. For example, fatty infiltration of the centrilobular region of the liver occurred only in the more severely deficient of our rats. The rats of Deane \& Shaw (1947) survived for longer than ours, and it is reasonable to assume that they were less severely deficient and therefore did not show histologically any fat in the liver.

It was considered that frightening the rats at the time of killing might be a cause of depletion of the adrenocortical lipids. This would account for the failure of other workers to observe increased amounts of lipid in the adrenals of pyridoxin-deficient rats. Especial care was taken not to frighten the animals when they were being killed. For this reason an intraperitoneal injection of a solution of Nembutal was used to anaesthetize the rat rather than the more usual methods of killing. No signs of alarm were shown by any of the rats so killed, even at the time of the injection.

The great differences between the weights and histological structures of the organs taken from the two rats that received a single dose of ro $\mu \mathrm{g}$ of pyridoxin a fortnight before death and those of litter-mate rats totally deprived of the vitamin for the same period of 8 weeks seem noteworthy. These results agree with those of Stebbins (I950) who found that severely pyridoxin-deficient rats returned to normal after the injection of very small amounts of pyridoxin.

\section{SUMMARY}

I. Seventy-two rats of the Lister strain were divided into three groups of twentyfour. One group was given a purified diet fully supplemented with vitamins as separate doses (diet B); another group received the same diet but with pyridoxin omitted (diet A); the third group received the stock diet (diet C). All diets were given 
without stint, and eight rats from each group were killed after 3,6 and 8 weeks on the diet.

2. Rats fed on the pyridoxin-deficient diet $\mathbf{A}$ grew less well than those on diets $B$ and $C$. Their thymus weights were lower and adrenal weights higher, relative to bodyweight, than those of the controls.

3. No significant differences in relative weight or of histological structure were seen in the spleens of the seventy-two rats.

4. Histological changes in the adrenal and thymus glands preceded the fatty infiltration of the centrilobular region of the liver in the deficient rats.

5. It is suggested that the adrenal changes are indicative of overactivity of the zona fasciculata, which may have caused the changes in liver and thymus.

6. Reasons are suggested for the differences between these results and those of some other workers.

7. A single dose of ro $\mu$ g pyridoxin given after 6 weeks' deficiency of the vitamin prevented or delayed many of the changes in the thymus, adrenals, and liver in rats killed after deprivation for a further fortnight.

The author wishes to thank Miss A. M. Copping for her advice and help with the layout of the experiment, and Miss A. D. Trusler for her assistance with the weighings. Her best thanks are also due to Professor J. A. C. Knox for his interest and valuable advice in the preparation of the paper. Mr G. Willoughby gave assistance with the photography.

\section{REFERENCES}

Agnew, L. R. C. (1948). Nature, Lond., I6r, 205.

Agnew, L. R. C. \& Cook, R. (1949). Brit. F. Nutr. 2, 32 I.

Antopol, W. \& Unna, K. (1942). Arch. Path. 33, 241.

Batchen, J. M., Cheesman, E., Copping, A. M. \& Trusler, A. D. (1955). Brit. F. Nutr. 9, 49.

Best, C. H., Hartroft, W. S., Lucas, C. C. \& Ridout, J. H. (1955). Brit. med. F. i, I 439.

Christensen, K. \& Griffith, W. H. (1942). Endocrinology, 30, 575.

Copping, A. M. (r956). Personal communication.

Deane, H. W. \& Greep, R. O. (1946). Amer. F. Anat. 79, I 17.

Deane, H. W. \& Shaw, J. H. (1947). F. Nutr. 34, 1.

Himsworth, H. P. (1950). Lectures on the Liver and its Diseases, and ed., p. 12. Oxford: Blackwell. MacKay, E. M. \& Barnes, R. H. (1937a). Amer. F. Physiol. 118, 184.

MacKay, E. M. \& Barnes, R. H. (1937b). Amer. F. Physiol. 118, 525.

Mueller, J. F., Weir, D. R. \& Heinle, R. W. (1951). Proc. Soc. exp. Biol., N.Y., 77, 3 г 2.

Sayers, G. \& Sayers, M. A. (1948). Recent Progr. Hormone Res. 2, 8 I.

Stebbins, R. B. (1950). Endocrinology, 49, 25.

Stoerck, H. C. (1950). Proc. Soc. exp. Biol., N. Y., 74, 798.

Stoerck, H. C. \& Eisen, H. N. (1946). Proc. Soc. exp. Biol., N. Y., 62, 88.

\section{EXPLANATION OF PLATE}

Comparison of sections of liver, adrenal and thymus glands from a rat deprived of pyridoxin for 8 weeks $(A)$ and a litter-mate fed on a similar diet with the addition of pyridoxin $(B)$. Scott's haematoxylin and dilute Biebrich Scarlet. Liver: $A$ shows the areas of fatty infiltration around the centrilobular veins and some portal canals. (Black specks in both sections are artifacts.) $\times 72$. Adrenal: $A$ shows large lipid-containing cells in the zona fasciculata. The regular polyhedral cells of the fasciculata of $B$ contain only little lipid. $\times 228$. Thymus: $A$ shows loss of lymphocytes, especially from the cortex. The cortex and medulla of the control rat $(B)$ are very clearly defined by comparison. There is also increased vascularization of the medulla and increased interlobular connective tissue in the deficient rat. $\times 72$. 

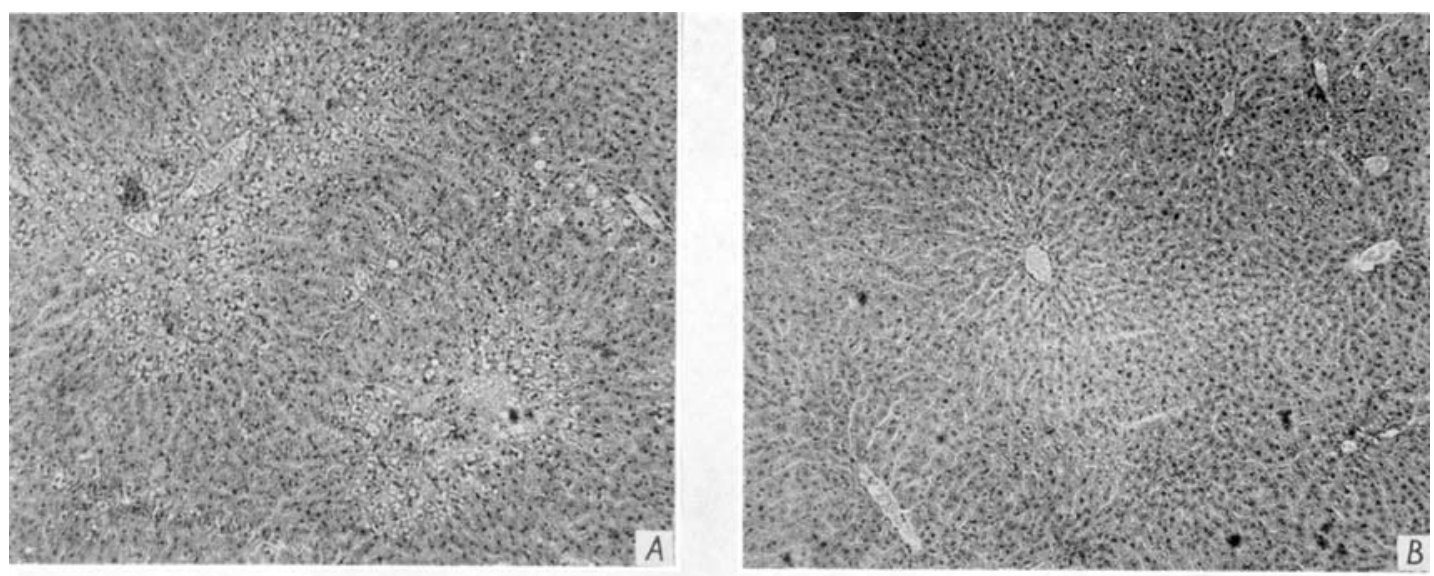

Liver
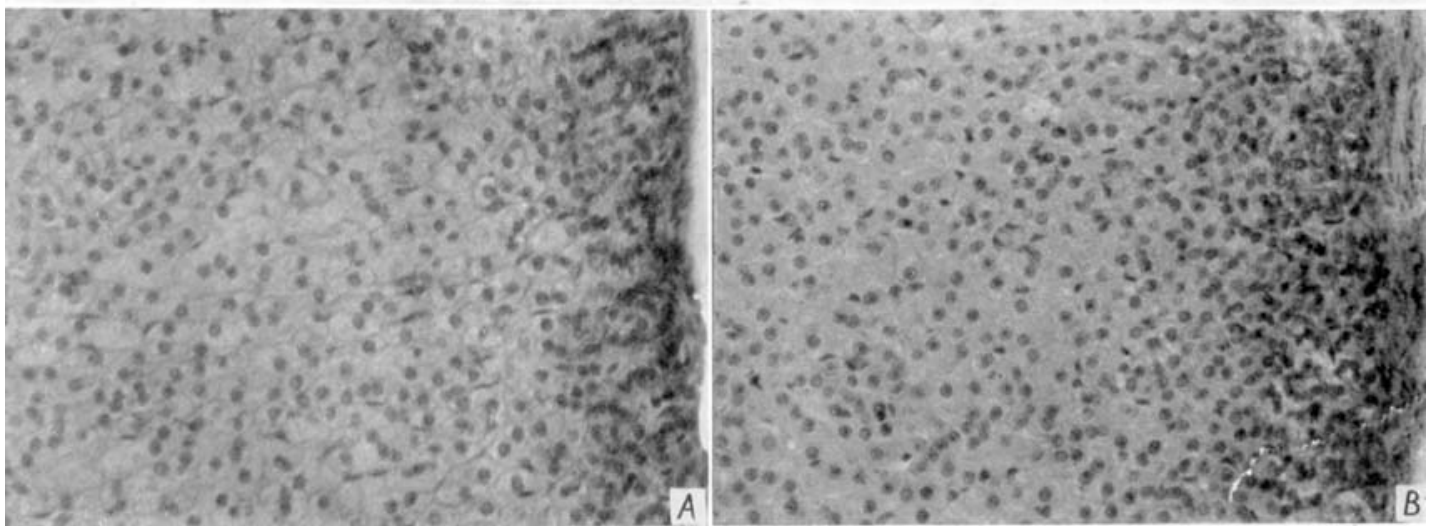

Adrenal
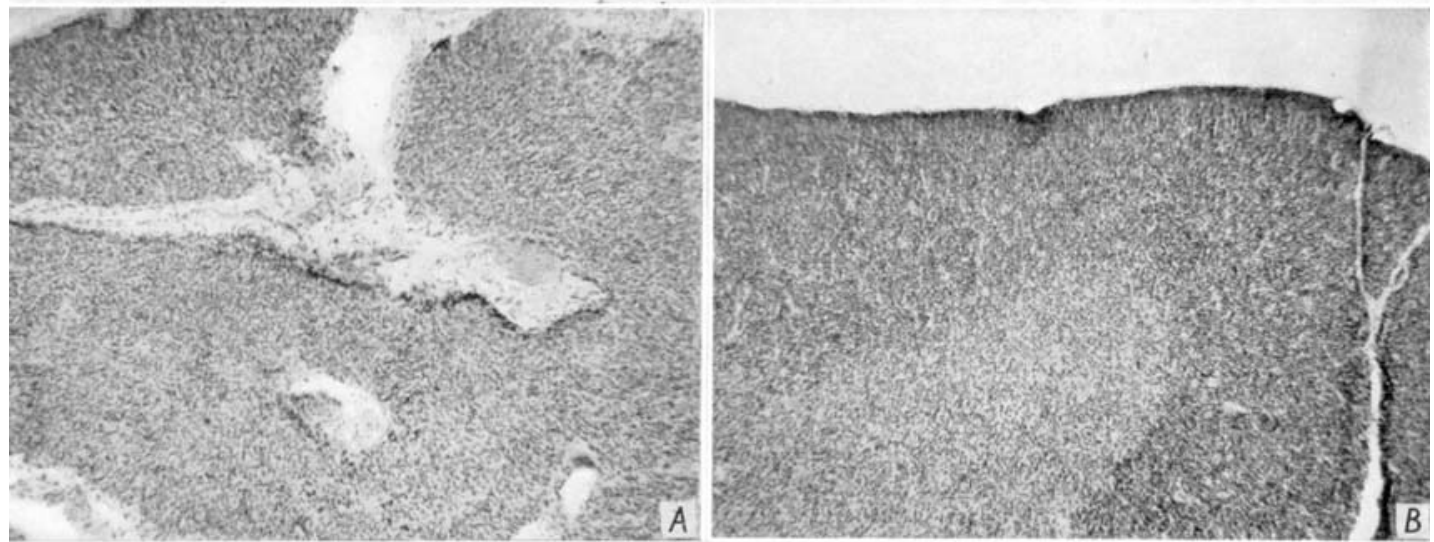

Thymus

British Fournal of Nutrition, Vol. ıо, No. 4 